\title{
Leaf Essential Oil Composition, Antioxidant Activity, Total Phenolic Content and Total Flavonoid Content of Pimenta Dioica (L.)Merr (Myrtaceae): A Superior Quality Spice Grown in Sri Lanka
}

\author{
Dharmadasa R.M ${ }^{1, *}$, Abeysinghe D.C ${ }^{2}$, Dissanayake DMN. Abeywardhane K.W. ${ }^{2}$, Fernando N.S. ${ }^{2}$ \\ ${ }^{1}$ Herbal Technology Section ,Industrial Technology Institute, Baudhaloka Mawatha, Sri Lanka \\ ${ }^{2}$ Department of Plantation Management, Faculty of Agriculture and Plantation Management, Wayamba University of Sri Lanka, \\ Gonawila (NWP)
}

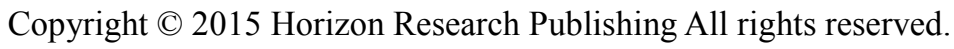

\begin{abstract}
Pimenta dioica(Linn.)Merill. (Myrtaceae) is well-renowned, industrially important, aromatic spice plant widely used in traditional systems of medicine, food, perfumery and cosmetic industries. Present study describes the essential oil content, composition, and antioxidant capacity of mature and immature leaves of Pimenta dioica. Essential oil was extracted using Clevenger-type apparatus for $5 \mathrm{hrs}$. Leaf essential oil composition was analyzed using GC-MS. Quantification of Total Antioxidant Capacity (TAC), Total Phenolic Content (TPC) and Total Flavonoid Content (TFC) were carried out using standard methodologies. The oil yield was $0.80 \%(\mathrm{v} / \mathrm{w})$ of fresh weight. Twelve compounds comprising more than $97 \%$ of total composition were identified by GC/MS analysis. Eugenol $(85.33 \pm 2.0 \%)$ was identified as a major constituent of essential oil and followed by $\beta$-caryophylene $(4.36 \pm 0.3 \%)$, cineole $(4.19 \pm 0.3 \%)$, linalool $(0.83 \pm 0.11 \%)$ and $\alpha$-humulene $(0.76 \pm 0.12 \%)$.Immature leaf extracts exhibited the marked Total Antioxidant Capacity (TAC) (537.18 $\pm 11.62 \mathrm{mg}$ trolox equivalent per g of sample); Total Phenolic Content (TPC) $(99.09 \pm 3.65 \mathrm{mg}$ Gallicacid equivalent per $\mathrm{g}$ of sample), and Total Flavonoid Content (TFC) $(136.71 \pm 3.24 \mathrm{mg}$ Rutin equivalent per $\mathrm{g}$ of sample). Presence of greater amount of eugenol in essential oil, TAC, TPC and TFC in leaf extracts undoubtedly demonstrated potential of Pimenta dioica essential oil and leaf material as a fabulous raw material for food, perfumery and cosmetic industries. Further harvesting of immature leaves could be suggested for better therapeutic benefits.
\end{abstract}

Keywords Essential Oil, Eugenol, Myrtaceae, Pimenta dioica, Total Antioxidant Capacity, Total Phenolic Content

\section{Introduction}

Pimenta dioica(Linn.)Merill. (Myrtaceae) is well known for its characteristic aroma, therapeutic and culinary qualities which resembles to aroma and flavor of Clove, Nutmeg Cinnamon and hence it is called Allspice [1,2]. Plant is known as, Jamaica pepper, myrtle pepper and Newspice in English. Further, P. dioica grows or cultivated in Jamaica, Cuba, Haiti, Brazil, Central America, West Indies, Venezuela, Mexico, Honduras, Guatemala and Grenada. This is a tropical, evergreen plant which grows up to $15 \mathrm{~m}$ tall with a pale brown bark, twigs flattened. Leaves are opposite, petiolate, blades narrowly elliptic or oblong [3]. Moreover, powdered leaves or seeds are widely consumed as cuisines of Middle East and Central America as well in European pastries [4].

Leaves and seeds are widely used in traditional medicine for the treatment of flatulence, diarrhea, neuralgia, rheumatism, digestive problems [5]. Moreover, it is valued for its secondary metabolites like essential oil with compositions, oleoresin which is highly utilized in food industry, perfumery and cosmetic products. The yield of the essential oil of fruits or leaves varied from $1-4.5 \%$ and the major constituents of essential oil is eugenol (70-80\%), cineole, humulene, caryophyllene [6,7]. Total Phenolic Content (TPC), Total Flavonoid Content (TFC) and Total Antioxidant Capacity (TAC) have been renowned as therapeutically active substances which regulate important physiological actions on the human body [8]. Since antioxidant function as free radical scavengers and quenchers of singlet oxygen formation, investigation of natural anti-oxidants has greatly increased in recent years [9]. Out of the commonly used spice crops, allspice is distinguished due to its multi aroma and flavor characteristics [10,11]. Although there are scattered information available on different phytochemicals present in this plant, comparative study on the most important maturity stages are yet to be studied. Therefore, present study mainly 
focus on investigation of important characteristics such as essential oil content and composition, total antioxidant capacity, total phenolic and total flavonoid contents of mature and immature leaves of Sri Lankan grown P. dioica.<smiles>C=CCc1ccc(O)c(OC)c1</smiles>

Figure 1. Chemical structure of eugenol

\section{Materials and Methods}

\subsection{Plant Materials}

Leaves of Pimenta dioica(Linn.)Merill. were collected from the home garden at Kandy district in Sri Lanka. These materials were identified and authenticated by comparing with the herbarium specimens deposited at the Royal Botanical Garden, Peradeniya, Sri Lanka. Herbarium specimen was prepared and deposited at Institutional herbarium (ITI/HTS/ 102).

\subsection{Extraction of Essential Oil}

Shade dried powdered materials (100 g) of leaves of Pimenta dioica were hydro-distilled in a Clevenger-type apparatus for $5 \mathrm{hrs}$. The extracted volatile oils were dried over anhydrous sodium sulphate and stored in sealed vials at $4^{\circ} \mathrm{C}$ until analysis. The yield of the oils was calculated based on dry weight of plant materials. Results are presented as means of triplicate and standard deviation.

\subsection{Extraction of Phytochemicals}

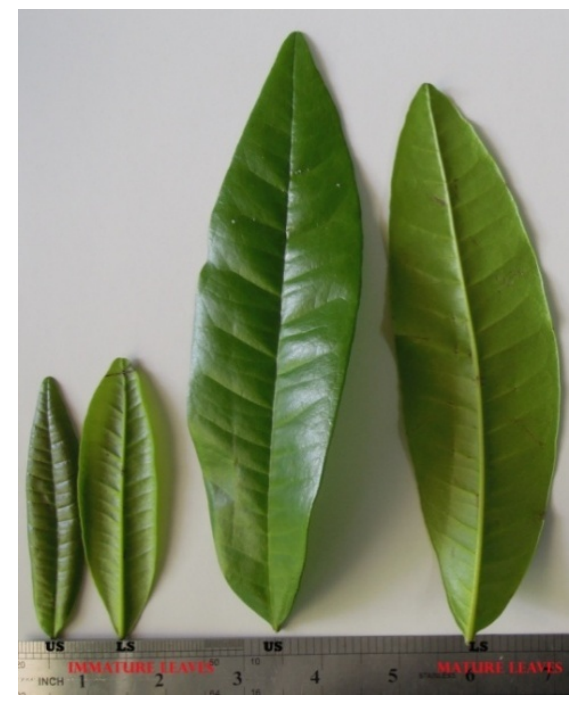

[US-upper surface; LS- lower surface]

Figure 2. Two maturity stages of leaves used for chemical analysis

As shown in figure 2, mature and immature leaf samples were cut into small pieces and air dried for three days at room temperature $\left(28 \pm 2^{\circ} \mathrm{C}\right)$. Then samples ( 3 samples from each category) were powdered using motor and pestle and sieved with $0.25 \mathrm{~mm}$ mesh. Powdered samples $(0.1 \mathrm{~g})$ were mixed with $5 \mathrm{~mL}$ of $80 \%$ methanol vortexed for 15 minutes. Then it was placed in a water bath at $60^{\circ} \mathrm{C}$ for 40 minutes and vortex procedure was repeated in 10 minutes interval. After centrifugation at $4,000 \mathrm{rpm}$ for 5 minutes, the supernatant was decanted into a $15 \mathrm{~mL}$ centrifuge tube and the remaining was re-extracted with $5 \mathrm{~mL}$ of $80 \%$ methanol.

\subsection{Gas Chromatography-Mass Spectrometry (GC-MS) Analysis}

GC-MS analysis was carried out on a Hewlett-Packard 6890 Gas Chromatograph fitted with a fused silica HP-5MS capillary column $(30 \mathrm{~m} \times 0.25 \mathrm{~mm}$; film thickness $0.25 \mu \mathrm{m})$. The oven temperature was programmed from $60-280^{\circ} \mathrm{C}$ at $4^{\circ} \mathrm{C} / \mathrm{min}$. Helium was used as carrier gas at a flow rate of $2 \mathrm{~mL} / \mathrm{min}$. Identification of components of essential oils were carried out based on retention indices and fragmentation patterns of the mass spectra available in W9N08 Whily version 9 and Nist version 8 libraries.

\subsection{The Total Phenolic Content (TPC)}

The total phenolic content was quantified using a modified Folin-Ciocâlteu method. Briefly, $4 \mathrm{~mL}$ of distilled water and $0.5 \mathrm{~mL}$ of properly diluted leaf extract were mixed with 0.5 $\mathrm{mL}$ of $0.5 \mathrm{~N}$ Folin-Ciocâlteu reagent (FCR) and allowed to react for 3 minutes. Then $1 \mathrm{~mL}$ saturated sodium carbonate solution was mixed and incubated in a water bath for $2 \mathrm{hrs}$ at $30{ }^{\circ} \mathrm{C}$. The absorbance was measured at $760 \mathrm{~nm}$ using UV visible spectrophotometer (Shimadzu UV-160). Gallic acid was used as the standard and data were expressed as mg of Gallic acid equivalent (GAE) /g DW.

\subsection{Quantification of Total Flavonoid (TFC)}

Total flavonoid content (TFC) was determined by a colorimetric method [12], with slight modifications. Briefly, $0.5 \mathrm{~mL}$ of the plant extract was diluted with $3.5 \mathrm{~mL}$ of distilled water. Then $0.3 \mathrm{~mL}$ of a $5 \% \mathrm{NaNO}_{2}$ solution was added to the mixture. After 6 minutes, $0.3 \mathrm{~mL}$ of a $10 \% \mathrm{Al}$ $\left(\mathrm{NO}_{3}\right)_{3} .6 \mathrm{H}_{2} \mathrm{O}$ solution was added, and the mixture was allowed to stand for another 6 minutes. Then $2 \mathrm{~mL}$ of $2 \mathrm{M}$ $\mathrm{NaOH}$ was added, and top up to $8 \mathrm{~mL}$ with distilled water. After thoroughly mixing, the absorbance was measured at $510 \mathrm{~nm}$ using UV visible spectrophotometer (Shimadzu UV-160, Japan). Rutin was used as the standard and data were expressed as $\mathrm{mg}$ of rutin equivalent (RE)/g DW.

\subsection{Determination of Total Antioxidant Capacity (TAC)}

Total antioxidant capacity was determined using Ferric Reducing Antioxidant Power (FRAP) assay[14]. Methanolic leaf extract $(100 \mu \mathrm{L})$ was mixed with $900 \mu \mathrm{L}$ of freshly 
prepared FRAP reagent of $\mathrm{pH} 3.6$ containing $2.5 \mathrm{~mL}$ of 10 mol/L, 2,4,6-Tripyridyl-s-Triazine (TPTZ) solution in 40 $\mathrm{mmol} / \mathrm{L}, \mathrm{HCl}$ plus $2.5 \mathrm{ml}$ of $20 \mathrm{mmol} / \mathrm{L} \mathrm{FeCl}_{3}$ and $25 \mathrm{~mL}$ of $300 \mathrm{~mol} / \mathrm{L}$ acetate buffer. Absorbance was measured at 593 $\mathrm{nm}$ using the spectrophotometer (Shimadzu, UV Mini 1240, Japan) after incubating for 4 minutes. The trolox was used as the standard solution and TAC was expressed as mg trolox equivalents (TE) /g DW.

\section{Results and Discussion}

Spices have been identified as important ingredients in the food industry since the beginning of the history. Therefore, in the present study attempts have been made to investigate the leaf essential oil content and composition, antioxidant activity and some bioactive compounds of mature and immature leaves of Pimenta dioica (Figure 1).

The oil yield was $0.8 \%(\mathrm{v} / \mathrm{w})$ of fresh weight of allspice leaves. As demonstrated in Table 1, twelve compounds comprising more than $97 \%$ of total composition were identified using GC/MS analysis. Among those, eugenol $(85.33 \%)$ which is an integral part of many spices exhibiting an array of therapeutic effects on analgesic, local anesthetic, anti-inflammatory, and antibacterial effects as the major component, followed by $\beta$-caryophylene (4.36\%) and cineole $(4.19 \%)$ linalool $(0.83 \pm 0.11), \quad \alpha$-humulene $(0.76 \pm 0.12)$. Results of the present study are in agreement with previous studies conducted by Padmakumari,2011) who investigated essential oil composition and found that essential oil of Pimenta dioica consist eugenol (74.71\%), methyl eugenol (4.08\%) and caryophylene (4.90\%). Interestingly, presence of notable eugenol, $\beta$ - caryophylene and cineole contents are comparable or higher than percentages of these constituents presence in major eugenol sources like cinnamon bark, and clove bud oil which are considered as major spice crops used all over the world $[2,13,15]$.

Table 1. Composition of the essential oils of Pimenta dioica (L.)Merr. (Myrtaceae)

\begin{tabular}{ccc}
\hline Retention time & Compound name & Compound \% \\
\hline 14.61 & $\alpha$-pinene & $0.14 \pm 0.01$ \\
14.91 & $\beta$-pinene & $0.15 \pm 0.01$ \\
16.51 & $\beta$-myrcene & $0.07 \pm 0.02$ \\
17.25 & Limonene & $0.56 \pm 0.01$ \\
20.08 & Linalool & $0.83 \pm 0.11$ \\
17.58 & Cineole & $4.19 \pm 0.3$ \\
22.21 & $\alpha$-terpineol & $0.48 \pm 0.01$ \\
23.79 & Chavicol & $0.33 \pm 0.01$ \\
25.65 & Eugenol & $85.33 \pm 2.0$ \\
28.06 & $\beta$ - caryophylene & $4.36 \pm 0.3$ \\
29.14 & $\alpha$-humulene & $0.76 \pm 0.12$ \\
29.87 & Germacrene & $0.29 \pm 0.02$ \\
\hline
\end{tabular}

Table 2. Total phenol content, total flavonoid content and antioxidant capacity of immature and mature leaf samples of Pimenta dioica (L.) Merr.

\begin{tabular}{cccc}
\hline Sample & $\begin{array}{c}\text { TAC (mg TE/g } \\
\text { DW) }\end{array}$ & $\begin{array}{c}\text { TPC (mg } \\
\text { GAEg DW) }\end{array}$ & $\begin{array}{c}\text { TFC (mg RE / g } \\
\text { DW) }\end{array}$ \\
\hline $\begin{array}{c}\text { Immature } \\
\text { leaf }\end{array}$ & $537.18 \pm 11.62$ & $99.09 \pm 3.65$ & $136.71 \pm 3.24$ \\
Mature leaf & $406.00 \pm 3.01$ & $94.15 \pm 2.14$ & $61.81 \pm 1.62$ \\
\hline
\end{tabular}

As demonstrated in Table 2, we investigated TPC, TFC and TAC of mature and immature leaves which are highly abundance and widely used as a major ingredient in traditional medicine, perfumery, food and cosmetic industries. Results clearly revealed that all tested parameters such as TPC (99.09 GAE mg /g DW), TFC (136.71 mg RE/g $\mathrm{DW})$ and $\mathrm{TAC}(537.18 \mathrm{mg} \mathrm{TE} / \mathrm{g} \mathrm{DW})$ are greater in methanolic extracts of immature leaves of $P$. dioica. In general, the spices belonging to Myrtaceae family are rich in polyphenols and antioxidant activity[10, 16, and 17]. Further, presence of higher content of TPC, TFC and TAC in immature leaves might be due to the less cellulose and/or pectin in immature leaves or/and the active components present in tender parts are more soluble than those present in mature parts. Observed high TAC, TPC and TFC in immature leaf extracts are in agreement with previous studies [18], who investigated the higher TAC, TPC and TFC in immature tea leaves.

In the present study we observed distinctive values for eugenol content $(85.33 \%)$ and TAC in leaves $(537.18 \mathrm{mg} \mathrm{TE}$ (g DW) which are comparable or higher the values observed in other spices used in different parts of the world. Moreover, since allspice reflects the aroma and flavor resemble to many distinguished spices like clove, nutmeg and cinnamon, present study open an avenue for development of highly nourishing spice product using Pimenta dioica mature and immature leaves.

\section{Conclusions}

Presence of greater amount (85\%) of eugenol in essential oil, and marked total Antioxidant Capacity (TAC), Total Phenolic Content (TPC) and Total Flavonoid Content (TFC) TAC, TPC and TFC in leaf extracts undoubtedly demonstrated potential of Pimenta dioica essential oil and leaf material as a fabulous raw material for food, perfumery and cosmetic industries. Further harvesting of immature leaves could be suggested for better therapeutic benefits.

\section{Conflict of Interest}

Authors declare that there is no conflict of interest

\section{Acknowledgements}

Authors wish to acknowledge Mr. ALM Aththanayake for his kind assistance 


\section{REFERENCES}

[1] Weiss, E.A.,2002. Spice Crops CAB Publishing USA. 104-120.

[2] Neal, M. C. In Gardens of Hawaii. Bernice P. (1965). Bishop museum special publication, Bishop Museum Press, Honolulu, HI.40.

[3] Lorence., David H., Flynn., Timothy W., Wagner., Warren L. (1995). "Contributions to the Flora of Hawaii III". Bishop Museum Occasional Papers, Hawaii Bishop Museum Press, Honolulu. 41, 19-58. ISSN 0893-1348. Retrieved 12 December 2009

[4] Lei Zhang and Bal L. Lokeshwar.(2012).Medicinal Properties of the Jamaican Pepper Plant Pimenta dioica and Allspice.Curr Drug Targets. 13(14), 1900-1906.

[5] Anonymous, (1969).Wealth of India (Raw Materials).Publications Information Division, CSIR Publications. New Delhi.8, 58-59.

[6] Maringiu B., Piras A., Porcedda S., Casu R., Oierucci P. (2005) Comparative Analysis of Supercritical $\mathrm{CO}_{2}$ Extract and oil of Pimenta dioica Leaves. Journal of. Essent Oil 17, 530-532.

[7] Tucker, A.O., Maciarello, J., Landrum, L.R., (1991). Volatile leaf oils of caribbeanMyrtaceae. II. Pimenta dioica(L.) Merr.of Jamaica. Journal of Essent Oil Res3, 195-196.

[8] Chandur, U., Shashidhar, S., Chandrasekar, S, B., Bhanumathy, M., Midhun, T. (2011). Phytochemical evaluation and anti- arthritic activity of root of Saussurealappa.Pharmacologia2, 265-267

[9] Kaufman, P.B., Cseke, L.J., Warber, S., Duke, J.A. and Brielmann, H.L. (1999).Natural Products from Plants,CRC Press, Boca Raton, FL.

[10] Lilian Regina Barros Mariutti., Gisela Pizarro de MattosBarreto.,NeuraBragagnolo and Adriana
ZerlottiMercadante. (2008). Free radical scavenging activity of ethanolic extracts from herbs and spices commercialized in Brazil. Brazilian Archives of Biology and Technology 51(6), 1225-1232.

[11] Jirovetz, L., Buchbauer.,Gstoilova,I., Krastanov, A., Stoyanova, A., Schmidt, E. (2007). Spice plants, Chemical composition and antioxidant properties of PimentaLindl. Essential oils, part 1: Pimenta dioica(L.) Merr.leaf oil from Jamaica. Ernährung/nutrition, 31, 55-63.

[12] Liu, M., Li, X.Q., Weber, C., Lee, C.Y., Brown, J., Liu, R.H. (2002) .Antioxidant and anti-proliferative activities of raspberries.Journal of Agric. Food Chem. 50(10), 2926-2930.

[13] Seongwei Lee., Musa Najiah., Wee Wendy., Musa Nadirah. (2009). Chemical composition and antimicrobial activity of the essential oil of Syzygium aromaticum flower bud (Clove) against fish systemic bacteria isolated from aquaculture sites. Frontiers of Agriculture in China, 332-336.

[14] Benzie, I.F.F., Strain, J.J. (1996). Ferric reducing ability of plasma (FRAP) as a measure of antioxidant power. The FRAP assay. Anal Biochem 239, 70-76.

[15] Paranagama, P.A., Wimalasena, S., Jayawardane, G.S., Senanayake, U.M., and Mubarak, A.M. (2001). A composition of essential oil constituents in bark, leaf, fruit and root oil of cinnamomum zelanicum grown in Sri Lanka. Journal of National Science Foundation of Sri Lanka, 29, 147-153.

[16] Hossain,M., Brunton, N., Barry-Ryan, C., Martin-Diana, A., Wilkinson, M. (2008) .Antioxidant Activity of Spice Extracts and Phenolics in Comparison to Synthetic Antioxidants.Rasayan Journal of Chemistry. 4(1), 751-756.

[17] Mohamed, S. A., Marzouk.,Fatma, A., Moharram ., Mona, A., Mohamed., Amira, M., Gamal-Eldeen., and Elsayed, A., Aboutabl. (2007) Anticancer and Antioxidant Tannins from Pimenta dioica Leaves.Natur forsch.62, 526-536.

[18] Ming Yuan., Xuejing.,Jia., Chunbang Ding., Shu Yuan., Zhongwei Zhang., and Yanger Chen. (2014). Comparative Studies on Bioactive Constituents in Hawk Tea Infusions with Different Maturity Degree and Their Antioxidant Activities.The Scientific World Journal.1-7. 